\title{
A first report on fracture toughness of bcc iron alloys as influenced by solutes: opposite effects of silicon and cobalt
}

\author{
M SRINIVAS, G MALAKONDAIAH and P RAMA RAO \\ Defence Metallurgical Research Laboratory, P O Kanchanbagh, Hyderabad 500 258, India \\ MS received 21 November 1988
}

\begin{abstract}
The effect of solutes on resistance to fracture of body centred cubic iron singlephase solid-solution alloys has been investigated. The $J$-integral method has been used for the measurement of ductile fracture toughness. The $J_{\text {IC }}$ values so determined quantitatively indicate the extent of degradation in fracture toughness due to the addition of hardening solute silicon. Cobalt addition results in alloy softening. The measured $J_{\text {IC }}$ values clearly demonstrate the toughening effect of cobalt addition as a solute, which result renders the case of $\mathrm{Fe}-\mathrm{Co}$ solid-solution alloys interesting.
\end{abstract}

Keywords. Ductile alloys; alloy softening; fracture toughness $J_{\mathrm{IC}}$; alloy hardening; critical fracture stress; cleavage fracture.

\section{Introduction}

It is well-known that the deformation behaviour of iron is profoundly modified by the nature and concentration of the elements that are in solid solution. However, a corresponding level of understanding does not exist in regard to how solute additions influence fracture resistance of iron (for that matter any metal) as measured quantitatively in terms of fracture toughness parameters. In the context of current design criteria involving not only strength but also fracture toughness, and as a significant issue of scientific curiosity, a rigorous evaluation of the fracture behaviour of single-phase iron alloys, which constitute the basis for widely used engineering steels, is warranted.

To-date studies pertaining to the fracture resistance of body centred cubic $(b c c)$ iron and solid solutions of iron are limited and have been made in terms of either tensile ductility or the impact transition temperature, which parameters cannot be rigorously employed to quantify fracture toughness. The present investigation is part of a programme aimed at fracture toughness measurements of iron-based solid solution alloys by employing the $J$-integral method based on the elastic-plastic fracture toughness concept. This first report is to record an unequivocal suggestion of our studies that cobalt addition as a solute resultsy in enhancement of fracture toughness of $b c c$ iron alloys. The positive effect of cobalt additions on iron alloy toughness is highlighted when contrasted with the deleterious effect of additions of some of the alloy-hardening solutes. Accordingly, fracture toughness measurements of iron-silicon solid solutions have been made and included in this report.

\section{Experimental}

The base material Armco iron contained by wt. $\%, 0.007 \mathrm{C},<0.03 \mathrm{Mn}, 0.005 \mathrm{~S}$ and $0.003 \mathrm{P}$. Alloys of iron with silicon and cobalt at two concentration levels, i.e. 0.5 and $3.5 \mathrm{wt} \%$ silicon, and 0.5 and $5.0 \mathrm{wt} \%$ cobalt, were chosen. For this purpose 
$80 \mathrm{~kg}$ melts of each composition were vacuum induction melted using high purity silicon and cobalt, respectively. The ingots were homogenised, processed to the required size and subsequently subjected to thermal treatments (table 1) to develop a grain size (refers to the length of mean linear intercept, $\widetilde{L}$ ) of around $125 \mu \mathrm{m}$. Grain size was maintained nearly constant to eliminate the possible effects of this microstructural variable. In all the cases it was ensured that the grain shape was equiaxed and uniform in size over the entire cross-section. The cross-sections of the test specimens, incidentally, were quite large on account of the requirements of valid fracture toughness measurements (e.g. $130 \times 130 \mathrm{~mm}$ and $55 \mathrm{~mm}$ thick blanks in the case of Armco iron).

Deformation and fracture behaviour of the chosen iron alloys was evaluated through smooth as well as notch tensile and fracture toughness tests. Tensile tests were conducted on Instron 1185 at a nominal strain rate of $10^{-3} \mathrm{~s}^{-1}$ using cylindrical specimens of diameter $4.5 \mathrm{~mm}$ and gauge length $15 \mathrm{~mm}$. Notch tensile tests as per ASTM E 602-81 (1986) were conducted on $\mathrm{Fe}, \mathrm{Fe}-3.5 \mathrm{Si}$ and $\mathrm{Fe}-5.0 \mathrm{Co}$ alloys, employing specimens of $12.7 \mathrm{~mm}$ diameter with a V-notch of $60^{\circ}$ included angle. Multiple specimen $J-R$ curve method as per ASTM E 813-81 (1986) was employed to evaluate ductile fracture toughness $J_{\mathrm{IC}}$. Specimen configurations and dimensions used in $J_{\mathrm{IC}}$ testing are listed in table 2 . The crack blunting line required in the fracture toughness test procedure was based on actual stretch zone width measurements in the ISI-100A scanning electron microscope (SEM) as suggested in JSME SO01 (1981).

\section{Results and discussion}

\subsection{Tensile properties}

Tensile properties of bcc iron alloys investigated are given in table 3. Silicon addition increases the strength of iron markedly. Increase in $0.2 \%$ yield stress and UTS up to 130 and $80 \%$ respectively were obtained with $3.5 \%$ silicon addition. On the other hand, cobalt addition lowers the yield strength of iron without affecting its tensile strength. Reduction in yield strength of up to $40 \%$ has been observed with the addition of $0.5 \%$ cobalt. The extent of softening was seen to decrease with increasing cobalt content. Accordingly $5 \%$ cobalt addition leads to $25 \%$ decrease in

Table 1. Thermal treatments employed and the resulting grain sizes for iron and iron binary alloys.

\begin{tabular}{|c|c|c|}
\hline Material & Treatment & $\begin{array}{c}\text { Grain size } \\
\bar{L}(\mu \mathrm{m})\end{array}$ \\
\hline$\overline{\mathrm{Fe}}$ & Upset-forged at $1173 \mathrm{~K}+1023 \mathrm{~K} / 2 \mathrm{hr}, \mathrm{FC}^{*}$ & 118 \\
\hline $\mathrm{Fe}-0.5 \mathrm{Si}$ & $\begin{array}{l}\text { Hot-forged at } 1173 \mathrm{~K}+\text { hot-rolled at } 973 \mathrm{~K}+ \\
1223 \mathrm{~K} / 1 \mathrm{hr}, \mathrm{AC}\end{array}$ & 125 \\
\hline $\mathrm{Fe}-3.5 \mathrm{Si}$ & $\begin{array}{l}\text { Hot-forged at } 1173 \mathrm{~K}+\text { hot-rolled at } 973 \mathrm{~K}+ \\
1248 \mathrm{~K} / 1 \mathrm{hr}, \mathrm{AC}\end{array}$ & 140 \\
\hline $\mathrm{Fe}-0.5 \mathrm{Co}$ & Hot-rolled at $973 \mathrm{~K}+1148 \mathrm{~K} / 2 \mathrm{hr}, \mathrm{FC}$ & 130 \\
\hline $\mathrm{Fe}-5 \cdot 0 \mathrm{Co}$ & Hot-forged at $973 \mathrm{~K}+1148 \mathrm{~K} / 2 \mathrm{hr}, \mathrm{FC}$ & 125 \\
\hline
\end{tabular}

*FC-furnace cooled; AC-air cooled. 
Table 2. Specimen configurations and dimensions.

\begin{tabular}{lcccc}
\hline Material & Type & $\begin{array}{c}\text { Thickness } \\
(\mathrm{mm})\end{array}$ & $\begin{array}{c}\text { Width } \\
(\mathrm{mm})\end{array}$ & $\begin{array}{c}\text { Span } \\
(\mathrm{mm})\end{array}$ \\
\hline $\mathrm{Fe}$ & $\mathrm{CT}$ & 50.8 & 101.6 & - \\
$\mathrm{Fe}-0.5 \mathrm{Si}$ & $\mathrm{CT}$ & 19.0 & 38.0 & - \\
$\mathrm{Fe}-3 \cdot 5 \mathrm{Si}$ & $\mathrm{CT}$ & 12.7 & 25.4 & - \\
$\mathrm{Fe}-0.5 \mathrm{Co}$ & $\mathrm{CT}$ & 25.4 & 50.8 & - \\
$\mathrm{Fe}-5 \cdot 0 \mathrm{Co}$ & 3 point bend & 25.4 & 50.8 & 200 \\
\hline
\end{tabular}

${ }^{*} \mathrm{CT}$ - compact tension.

Table 3. Tensile properties of bcc iron alloys.

\begin{tabular}{lcccc}
\hline Material & $\begin{array}{c}0.2 \% \mathrm{YS}^{*} \\
(\mathrm{MPa})\end{array}$ & $\begin{array}{c}\text { UTS } \\
(\mathrm{MPa})\end{array}$ & $\begin{array}{c}\text { Reduction in area } \\
(\%)\end{array}$ & $n$ \\
\hline $\mathrm{Fe}$ & 180 & 296 & 86 & $0 \cdot 28$ \\
$\mathrm{Fe}-0.5 \mathrm{Si}$ & 225 & 385 & 68 & $0 \cdot 21$ \\
$\mathrm{Fe}-3 \cdot 5 \mathrm{Si}$ & 423 & 541 & 64 & $0 \cdot 15$ \\
$\mathrm{Fe}-0.5 \mathrm{Co}$ & 110 & 290 & 88 & $0 \cdot 30$ \\
$\mathrm{Fe}-5.0 \mathrm{Co}$ & 130 & 293 & 90 & $0 \cdot 35$ \\
\hline
\end{tabular}

*YS - yield strength.

yield strength of Armco iron. Silicon addition leads to a marked reduction in tensile ductility as well as work hardening exponent. On the other hand, the work hardening exponent and tensile ductility were found to increase with cobalt addition.

The increase in strength with the addition of silicon is in line with earlier investigations (Rees et al 1954; Leslie et al 1969; Ishii et al 1984) and this behaviour can be related to the atom size misfit parameter (Leslie 1972). Silicon with a smaller atomic size $\left(2.351 \times 10^{-10} \mathrm{~m}\right)$ contracts the iron lattice and produces a disproportionate amount of strengthening from a relatively small misfit.

On the other hand, iron and cobalt have nearly the same atomic size $(2.482 \times$ $10^{-10} \mathrm{~m}$ and $2.497 \times 10^{-10} \mathrm{~m}$ respectively). The reduction in yield strength of iron with cobalt addition, termed alloy softening, observed in the present study conforms to the observations reported recently by Ishii et al (1984). It is suggested in the literature (Rees et al 1951; Stoloff et al 1965; Ravi and Gibala 1969; Smialek et al 1970) that alloy softening could be because of decrease in solubility of interstitials. Cobalt increases the activity of carbon in ferrite and results in a $75 \%$ decrease in solubility of carbon in an Fe-5\% Co alloy (Petrova et al 1960).

\subsection{Fracture toughness}

$\mathrm{Fe}-\mathrm{Si}$ alloys: Addition of silicon leads to cleavage instability during monotonic loading. Figure 1 contains load vs. load line displacement (LLD) plot for Armco iron up to the point of onset of real crack growth (corresponding to $J_{\mathrm{IC}}$ ) recorded with $50 \mathrm{~mm}$ thick compact tension (CT) specimen and those for $\mathrm{Fe}-\mathrm{Si}$ alloys recorded with 19 and $12.7 \mathrm{~mm}$ thick compact tension specimens up to the point of instability. Though a direct comparison of the area under load-LLD plots is not possible as specimen dimensions vary, $J_{I C}$ values derived (table 4 ) clearly reflect the deleterious influence of silicon addition. 


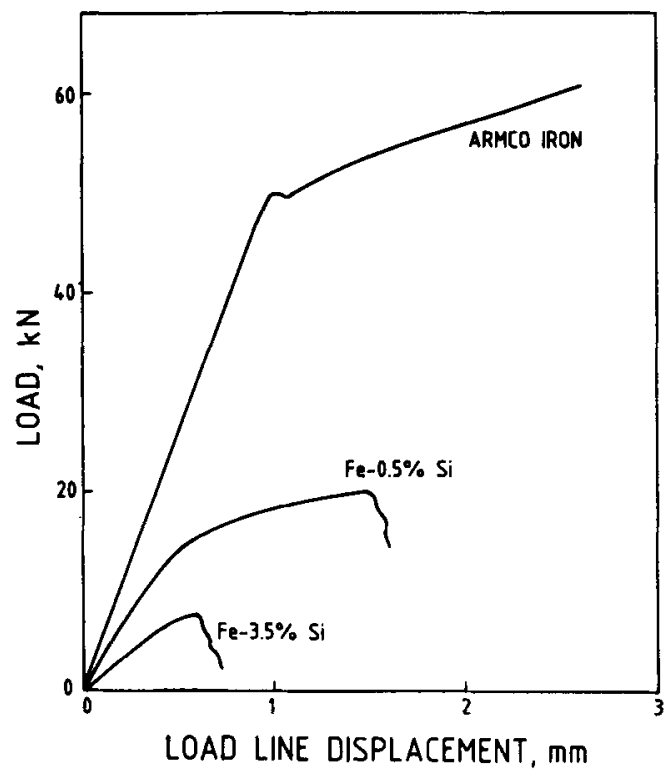

Figure 1. Load vs. load line displacement plots for Armco iron and iron-silicon alloys.

Table 4. $J_{\text {IC }}$ and other toughness parameters for bec iron alloys.

\begin{tabular}{lccc}
\hline & \multicolumn{3}{c}{$\begin{array}{c}\text { Area under stress- } \\
\text { strain curve } \\
\left(10^{-3} \mathrm{~kJ} / \mathrm{m}^{3}\right)\end{array}$} \\
\hline $\mathrm{Fe}$ & $\begin{array}{c}\text { Notch } \\
\left(\mathrm{kJ} / \mathrm{m}^{2}\right)\end{array}$ & 127 & yield ratio \\
$\mathrm{Fe}-0.5 \mathrm{Si}$ & 140 & 96 & $2 \cdot 5$ \\
$\mathrm{Fe}-3.5 \mathrm{Si}$ & 97 & 90 & - \\
$\mathrm{Fe}-0.5 \mathrm{Co}$ & 42 & 148 & $1 \cdot 5$ \\
$\mathrm{Fe}-5.0 \mathrm{Co}$ & 162 & 160 & - \\
\hline
\end{tabular}

As there was no detectable stable crack extension in either $\mathrm{Fe}-0.5 \mathrm{Si}$ or $\mathrm{Fe}-3.5 \mathrm{Si}$ alloys, $J$ corresponding to the onset of instability was taken as $J_{Q} . J_{Q}$ thus derived was subjected to validity checks (Clarke et al 1979; Ebrahimi and Ali 1988) to qualify $J_{Q}$ to be $J_{1 \mathrm{C}}$. In the case of iron, $J_{\mathrm{IC}}$ was derived from the $J-R$ curve established through the multiple specimen technique (figure 2a). As reported earlier (Srinivas et al 1987), the ASTM suggested blunting-line overestimates crack extension in Armco iron due to blunting. Stretch-zone width measurements, which therefore became necessary and were resorted to, have revealed that a constraint factor of 2, as against unity suggested in ASTM E 813-81 (1986) is appropriate for Armco iron. Hence $J_{1 \mathrm{C}}$ is derived using a blunting line drawn with a constraint factor of 2, i.e. $J=4 \sigma_{y t} \Delta a$, where $\sigma_{y t}$ is the average of yield and ultimate tensile strength and $\Delta a$ is crack extension. $J_{1 \mathrm{C}}$ values listed in table 4 indicate that the addition of silicon decreases the toughness drastically. An addition of $0.5 \% \mathrm{Si}$ has decreased the toughness of the base material Armco iron $\left(140 \mathrm{~kJ} / \mathrm{m}^{2}\right)$ by $30 \%$ whereas the same is decreased by $70 \%$ with $3.5 \% \mathrm{Si}$ addition.

$F e-C o$ alloys: $J$ vs. $\Delta a$ plots for iron alloys containing 0.5 and $5 \%$ cobalt are included in figure 2. Since $\mathrm{Fe}$ - Co alloys possess low strength and high work 

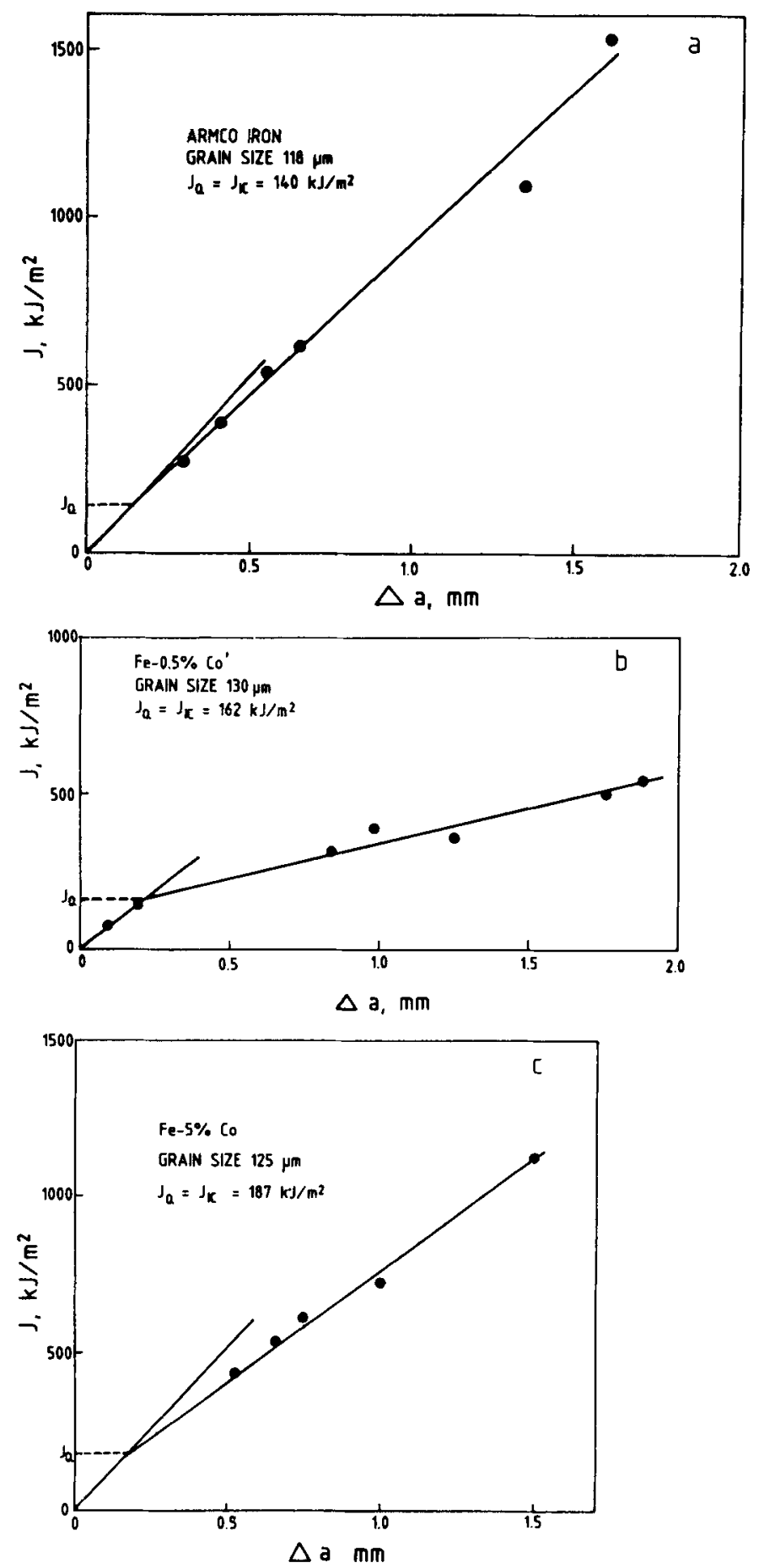

Figure 2. I $\triangle a$ plots for (a) Armco iron, (b) $\mathrm{Fe} 0.5 \% \mathrm{Co}$ and (c) $\mathrm{Fe} 5 \% \mathrm{Co}$

hardening, similar in this respect to Armco iron, a constraint factor of 2 was employed while drawing the blunting line. The validity of this assumption was 
confirmed through stretch-zone width measurements in the scanning electron microscope. Fracture toughness $J_{\text {IC }}$ thus derived (table 4) clearly reveal that cobalt addition enhances the toughness of the starting material Armco iron significantly. A $5 \%$ cobalt addition has led to nearly $35 \%$ increase in the fracture toughness.

The area under the engineering stress-strain curve (table 4), a parameter frequently employed as a measure of toughness, also indicates that cobalt addition toughens iron alloys whereas silicon embrittles. However, it is relevant to note that this parameter, though it rightly predicts toughening behaviour, fails to quantify the extent of toughening. Compare the per cent decrease in fracture toughness and area under stress-strain curve as a result of silicon addition. A $3.5 \%$ Si addition decreases the fracture toughness by $70 \%$ whereas the area under stress-strain curve reflects only a $30 \%$ decrease.

To further substantiate the fracture toughness data, notch tensile tests, recommended for toughness evaluation of low strength materials, were conducted. The notch tensile ratio, defined as the ratio of notch tensile strength and tensile yield strength derived from notch tensile tests is included in table 4 . The toughening influence of cobalt is again borne out.

Crack initiation in ductile alloys involves (a) the development of a plastic zone ahead of the crack tip, (b) void nucleation, growth and coalescence within the plastic zone. Energy expended in these processes largely governs the magnitude of fracture toughness $\left(J_{\mathrm{IC}}\right)$. On the other hand, cleavage fracture occurs in metals when their resistance to slip is so high that the cohesive strength is reached locally before the resistance to slip is overcome (Kelly et al 1967). The toughening due to cobalt is indicative of the effect of cobalt addition in further enhancing the energy spent in the ductile fracture process, whereas silicon, which causes a degradation in fracture toughness, leads to cleavage fracture.

For plastic deformation, yield stress and work hardening are important parameters. Lowering yield stress increases the plastic zone size as plastic zone size is inversely proportional to the square of the yield strength. Increasing the work hardening exponent $(n)$ has a similar effect. Hahn and Rosenfield (1968) have reported that critical plastic zone size at the crack tip $r^{*}$ varies with $n$ as $r^{*}=n^{2}$ where $r^{*}$ is in inches. Cobalt addition, resulting in lower yield strength and higher work hardening exponent when compared to Armco iron, leads to a larger plastic zone ahead of the crack tip, which renders the crack initiation process more difficult. It is also to be noted that the bond strength influences, at a fundamental level, the energy spent in the formation of the plastic zone, which increases with increasing bond strength. Cobalt addition increases the matrix as well as the grain boundary cohesive energy of iron (Hume-Rothery 1967; Seah 1980). The cohesive energy increases with the number of $s, p$ and $d$ electrons determined by the EngelBrewer correlation (Hume-Rothery 1967). Iron has eight electrons. Cobalt with nine such electrons improves the cohesive energy of iron. Further, segregation of interstitials to grain boundaries, as a result of cobalt addition, is known to contribute to increased grain boundary cohesion (Seah 1980).

In essentially particle-free microstructures such as those under consideration, cavity nucleation occurs due to slip band impingement with grain boundaries. Tensile data can be used to estimate the energy spent in cavity nucleation as well as in growth and coalescence. The area under the stress strain curve prior to and after necking increases with increasing cobalt addition (table 5). Rice and Tracey (1969) 
Table 5. Area under stress--strain curve before and after necking.

\begin{tabular}{lcc}
\hline & Area under stress-strain curve $\left(10^{-3} \mathrm{~kJ} / \mathrm{m}^{3}\right)$ \\
\cline { 2 - 3 } Material & Before necking & After necking \\
\hline $\mathrm{Fe}$ & 80 & 47 \\
$\mathrm{Fe} 0.5 \mathrm{Co}$ & 98 & 50 \\
$\mathrm{Fe}-5 \mathrm{Co}$ & 108 & 52 \\
\hline
\end{tabular}

have shown that a decrease in void growth rate is expected with increasing work hardening rate. Increased $n$ as a result of cobalt addition (table 3 ) is therefore expected to decrease the void growth rate. From the foregoing, it is evident that cobalt addition toughens the base material Armco iron by influencing the energy spent in the plastic zone formation as well as void nucleation, growth and coalescence.

Silicon-bearing alloys possess higher yield strength and lower work hardening exponents as compared to Armco iron; plastic zone size in $\mathrm{Fe}-\mathrm{Si}$ alloys, unlike the behaviour observed with $\mathrm{Fe}$ - $\mathrm{Co}$ alloys, is therefore restricted, which in turn leads to higher stress concentrations ahead of the crack tip. When the local stress concentration exceeds a critical fracture stress $\sigma_{f}$, cleavage fracture occurs. The $\sigma_{f}$ has been observed to be nearly the same for a given microstructural condition (Bowen et al 1986, 1987). Since the alloys under consideration have ferritic microstructure of constant grain size, $\sigma_{f}$ can be assumed to be nearly the same for all the alloys. The yield stress of iron at absolute zero i.e. $1100 \mathrm{MPa}$ (Gandhi and Ashby 1979) has been assumed to be $\sigma_{f}$ (Aurich and Wobst 1981). However, silicon addition lowers the cohesive energy of iron. Hence the cohesive strength of $\mathrm{Fe}-\mathrm{Si}$ alloys should be lower than the assumed cohesive strength of $1100 \mathrm{MPa}$. The local concentrated tensile stress near the crack tip attains a value nearly equal to 2.5 to 3 times the yield strength (Knott 1966). The increase in yield strength as a result of silicon addition leads to higher stress concentration at the crack tip region; consequently attainment of local stress to levels equivalent to $\sigma_{f}$ is more likely prior to yielding. The onset of cleavage fracture as a result of silicon addition leads to a drastic reduction in toughness of iron.

To summarise, the measured fracture toughness $J_{\text {IC }}$ and other toughness parameters listed in table 4 clearly establish that cobalt addition significantly improves the toughness of the base material Armco iron while silicon addition drastically decreases the same and the measurements show these effects quantitatively. Although the inference that alloy hardening is accompanied by loss in fracture toughness, and vice versa, has been drawn for several decades, quantitative measurements of toughness are clearly essential for any detailed analysis and understanding. Lack of a clear-cut measure of toughness as a material property in the past when alloy effects were the subject of intensive examination during the 1960s and the daunting experimental effort required as the $J$ integral for this purpose came to be established in the 1980s have been responsible for the absence of such studies so far. The present work is aimed at filling the gap and is also inspired by the thought that quantitative measurement of fracture toughness of alloys as influenced by solutes will lead to a basic understanding of the origins of fracture resistance. This is bound to be useful in the design of engineering alloys for which fracture toughness is being 
increasingly seen as an important criterion along side the strength parameters, yield strength and UTS. Considerable further work has been undertaken by the authors and the results will form a series of forthcoming papers.

\section{Acknowledgements}

The authors are thankful to Dr G Sundararajan for helpful discussions.

\section{References}

ASTM E 602-81 1986 Standard method for sharp-notch tension testing with cylindrical specimens, Annual Book of ASTM Standards (Philadelphia: American Society for Testing and Materials) Section 3, p. 635

ASTM E 813-81 1986 Standard method for $J_{\text {IC }}$. A measure of fracture toughness, Annual Book of ASTM Standards, (Philadelphia: American Society for Testing and Materials) Section 3, p. 768

Aurich D and Wobst K 1981 Arch. Eisenhuettenwes. 52201

Bowen P, Druce S G and Knott J F 1986 Acta Metall. 341121

Bowen P. Druce S G and Knott J F 1987 Acta Metall. 351735

Clarke G A, Andrews W R, Begley J A, Donald J K, Embley G T, Landes J D, McCabe D E and Underwood J H 1979 J. Test. Eval. 749

Ebrahimi F and Ali J A 1988 J. Test. Eval. 16113

Gandhi C and Ashby M F 1979 Scr. Metall. 13371

Hahn G T and Rosenfield A R 1968 ASTM STP 4325

Hume-Rothery W 1967 Prog. Mater. Sci. 13229

Ishii H, Kawarazaki T and Fujimora Y 1984 Metall. Trans. A15 679

JSME S001 1981 Japanese Society of Mechanical Engineers, Tokyo

Kelly A, Tyson A and Cottrell A H 1967 Philos. Mag. 15567

Knott J F 1966 J. Iron Steel Inst. 204104

Leslie W C 1972 Metall. Trans. 35

Leslie W C, Sober R J, Babcocik S G and Green S J 1969 Trans. Am. Soc. Met. 62690

Petrova E F, Lapshina M I and Shvartsman L A 1960 Met. Sci. Heat Treat. Met. 422

Ravi K V and Gibala R 1969 Scr. Metall. 3547

Rees W P, Hopkins B E and Tippler H R 1951 J. Iron Steel Inst. 169 157

Rees W P, Hopkins B E and Tippler H R 1954 J. Iron Steel Inst. 17693

Rice J R and Tracey D M 1969 J. Mech. Phys. Solids 17201

Seah M P 1980 Acta Metall. 28955

Smialek R L, Webb G L and Mitchell T E 1970 Scr. Metall. 433

Srinivas M, Malakondaiah G and Rama Rao P 1987 Eng. Fract. Mech. 28561

Stoloff N S, Davies R G and Ku R C 1965 Trans. Metall. Soc. AIME 2331500 